\title{
Bases documentales para el estudio de la teoría arquitectónica (1814-1858) en la Real Academia de Bellas Artes de San Fernando
}

\author{
M. a Del Rosario Santamaría Almolda
}

Fernando VII en el año de 1814, nada más regresar a España después de finalizada la Guerra de la Independencia, publicó una «Real Cédula» que renovaría las Reales resoluciones anteriores acerca de la aprobación de arquitectos ${ }^{1}$. En esta Real Cédula hacía saber que ningún Tribunal, Juez o Magistrado de la Corte concediese título o facultad para poder medir, tasar, o dirigir fábricas sin que precediese el examen y aprobación que le diese la Academia de ser hábil para estos menesteres, declarándose nulo y de ningún valor ni efecto cualquiere título que sin estas circunstancias se concediese. Y que ningún Tribunal, Ciudad, Villa ni cuerpo alguno eclesiástico o secular concediese el título de arquitecto a quién no se hubiese sujetado al examen riguroso de la Academia de San Fernando o de la de San Carlos en el reino de Valencia. Asimismo quedarian abolidos los «privilegios» que conservaban algunos pueblos de poder dar títulos de arquitectos arbitrariamente. Se prohibía expresamente a todas las Juntas, Congregaciones o Cofradías establecidas o que se intentasen establecer en la Corte para reglar los estudios y práctica de las tres Nobles Artes, y con especialidad "La que se dice de nuestra Señora de Belén, sita en la parroquial de S. Sebastián de esta Corte, pudiendo todos sus cofrades continuar en los exercicios de piedad y devoción que con aprobación legítima hubiesen abrazado; pero no usurpar los títulos de Colegio

Archivo Academia de Bellas Artes de San Fernando. Real Cédula de S.M. y Señores del Consejo por la cual se renuevan las Reales resoluciones acerca de la aprobación de Arquitectos y Maestros de Obras, lo que debe proceder indispensablemente a su execución, nombramiento de Arquitectos y sus calidades, y lo demás que se expresa. Madrid, Imprenta Real, 1814. Leg.: 17/3/1 (desde ahora A.A.S.F.). 
de Arquitectos, Academia de Arquitectura u otros semejantes»². Es decir, únicamente la Real Academia de San Fernando o la de San Carlos de Valencia, podían dar títulos de arquitectos y maestros de obras y siempre que los aspirantes se hubiesen sujetado a riguroso examen. Después con el transcurso del tiempo fueron apareciendo otras academias en Sevilla, Valladolid y Zaragoza también con potestad de poder examinar y dar títulos de arquitectos.

Posteriormente la Real Academia de Bellas Artes de San Fernando en la ORDENANZA ARTÍSTICA publicada a raíz de la Real Orden de 28 de agosto de 1816, firmada en Palacio por Pedro Ceballos ${ }^{3}$, comunicaba asimismo en el Capítulo Segundo todo lo concerniente a la profesión de arquitecto en 14 artículos. Los comprendidos desde el $3^{\circ}$. al $9^{\circ}$., especificaban, concretamente, todo lo relacionado a los exámenes de los aspirantes a dicho título.

Para ser admitidos a examen los futuros arquitectos tenían que presentar un edificio de su invención en planta, fachada y corte todo geométrico, previa constancia si no fuesen discípulos de la Academia, de dónde y qué estudios habian realizado, y unos y otros la acreditación de la práctica de dos años por lo menos al lado de académico o arquitecto. Este edificio debía ser uno de los de primer orden y los trabajos realizados llamados PRUEBA DE PENSADO se componían de dos partes:

- El informe práctico facultativo que comprendía la ubicación, plantas, fachadas, método constructivo y cálculo del proyecto.

- Los planos del edificio en planta, fachada y corte todo geométrico $y$ a igual escala de un regular tamaño.

Estos planos con el informe facultativo se presentarían en la Secretaría de la Academia, donde pasarían a la Comisión de Arquitectura para que se examinasen y en la primera Junta ordinaria, se daría aviso al pretendiente - si era favorable el informe-, para que presentase memorial a la Academia para hacer los demás ejercicios de examen. Estos trabajos presentados y denominados PRUEBAS DE PENSADO, eran edificios constructivos de beneficio general como hospitales, teatros, ayuntamientos, bibliotecas públicas, templos, cuarteles, museos, cementerios, etc. etc.,

2 Ibidem, Real Cédula, p. 1.

3 A.A.S.F. Ordenanza publicada a raiz de la Real Orden de S.M. de 28 de agosto de 1816, firmada por D. Pedro CEBallos para el más exacto cumplimiento de quanto corresponde a las funciones de los Profesores en el noble Arte de la Arquitectura, gobierno de los mismos y requisitos que han de concurrir para su aprobación. Leg.: 17/3-1. 
demostrando dichos aspirantes al título estar a la altura de los conocimientos tanto técnicos como teóricos en los métodos constructivos y materiales utilizados, así como de las discursiones que tenían lugar en las diferentes academias científicas europeas en cuanto a tipologías arquitectónicas.

Después, los aspirantes al título de arquitectos, harían una segunda prueba llamada PRUEBA DE REPENTE, que como su nombre nos indica debía de realizarse en un tiempo máximo de 15 horas contadas desde las siete de la mañana hasta las diez de la noche y en las aulas de la Academia de San Fernando. Se les dejaba, asimismo, utilizar los libros clásicos de la Arquitectura que existían y poseía la Academia en su biblioteca. Esta prueba consistía en elegir un tema de entre los tres extraídos al azar por el Vice-protector al meter tres veces la plegadera en el libro de asuntos para arquitectos. Este libro se componía de 150 temas ${ }^{4}$, y tenían que realizar en el tiempo estipulado de las 15 horas temas como:

«№. 17. Un depósito o arca de agua general en lo más alto de una gran población que sinviéndola de adorno, vierta su sobrante por fuentes alrededor: planta y fachada».

«№. 21. Un gabinete ricamente adornado para una señora principal, con su alcoba en el testero y las piezas de ingreso, tocador y demás servicio. Planta y alzado".

«№. 69. Un hospital para 100 enfermos con todas las proporciones y comodidades correspondientes. Planta, fachada y corte.

«№. 150. Una glorieta para entrada de un jardín público, con grupos laterales para habitaciones de guardas. Planta y alzados».

En el Capítulo Segundo artículo octavo de la Ordenanza Artística, se hace constar que para asegurar la escrupulosa exactitud para la realización de este ejercicio "estará el libro de asuntos bajo llave en la mesa de la sala de juntas desde que se concluya la ordinaria hasta la mañana del día siguiente, en que presentándose el pretendiente en la Academia le manifestará el conserje los tres programas numerados, y hecha la elección de uno volverá a encerrar el libro: $Y$ a fin de que nadie sepa los asuntos que han salido en suerte se pondrán registros de papel, y en el margen del memorial del pretendiente se escribirán los tres números sorteados sin tenerlos en público" ${ }^{5}$. Se pone de manifiesto con estas disposiciones, el que

4 A.A.S.F. Libro de asuntos para arquitectos. Este libro comprende los 150 temas que componian la denominada Prueba de Repente, cuya superación era requisito indispensable para obtener el título de Maestro Arquitecto. Signatura 333/3.

5 A.A.S.F. Ordenanza Artística. Capítulo Segundo, op. cit. 

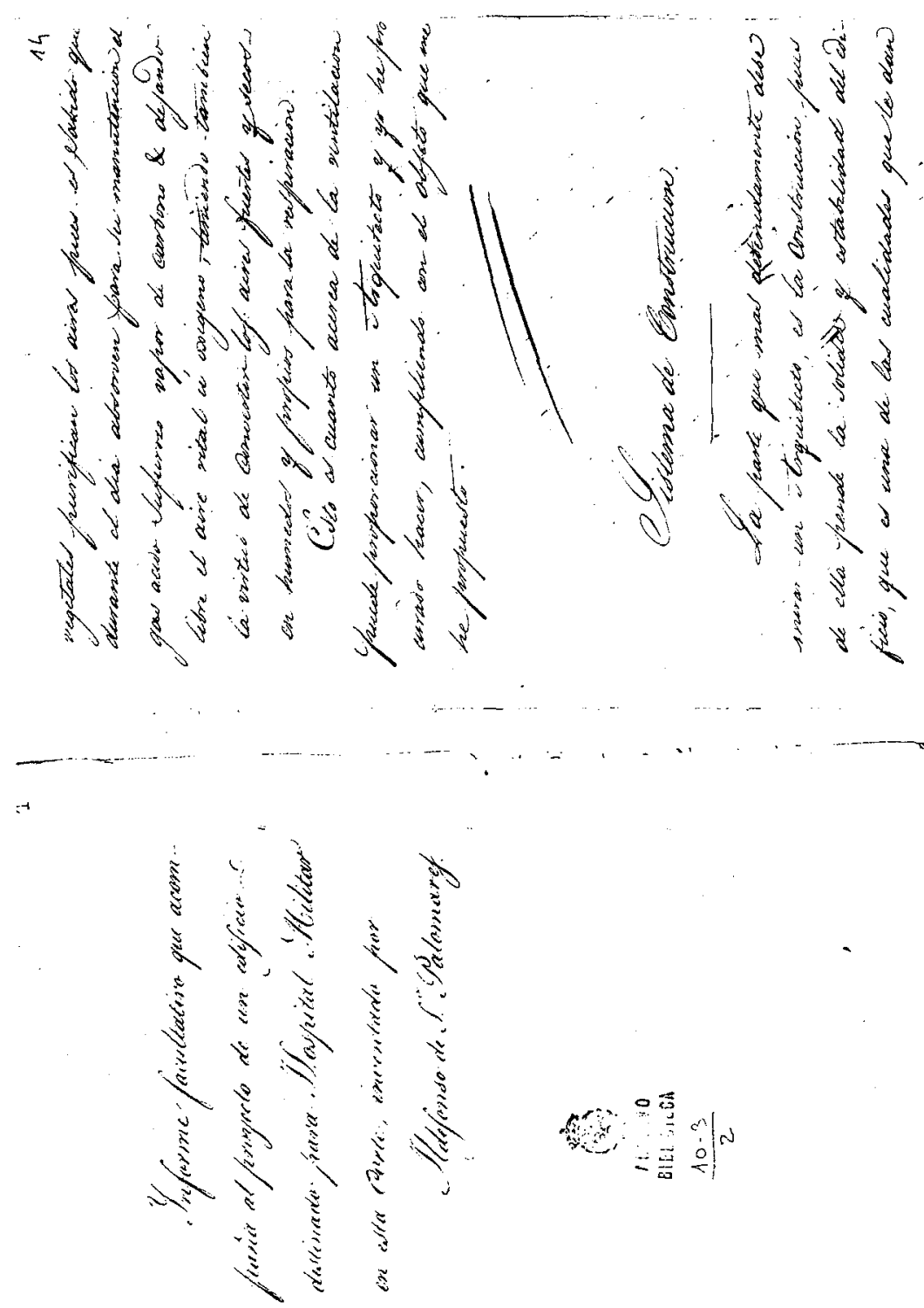

Fig. 1. Prueba de Pensado de D. Ildefonso de Santiago Palomares. Informe Facultativo de un Hospital Militar. Madrid, 28 de enero de 1838. (En estos informes desarrollaban el método constructivo utilizado, materiales y coste presupuestario). Archivo de la Real Academia de Bellas Artes de San Fernando. Leg. 10/3-2, pp. 1 y 14. 


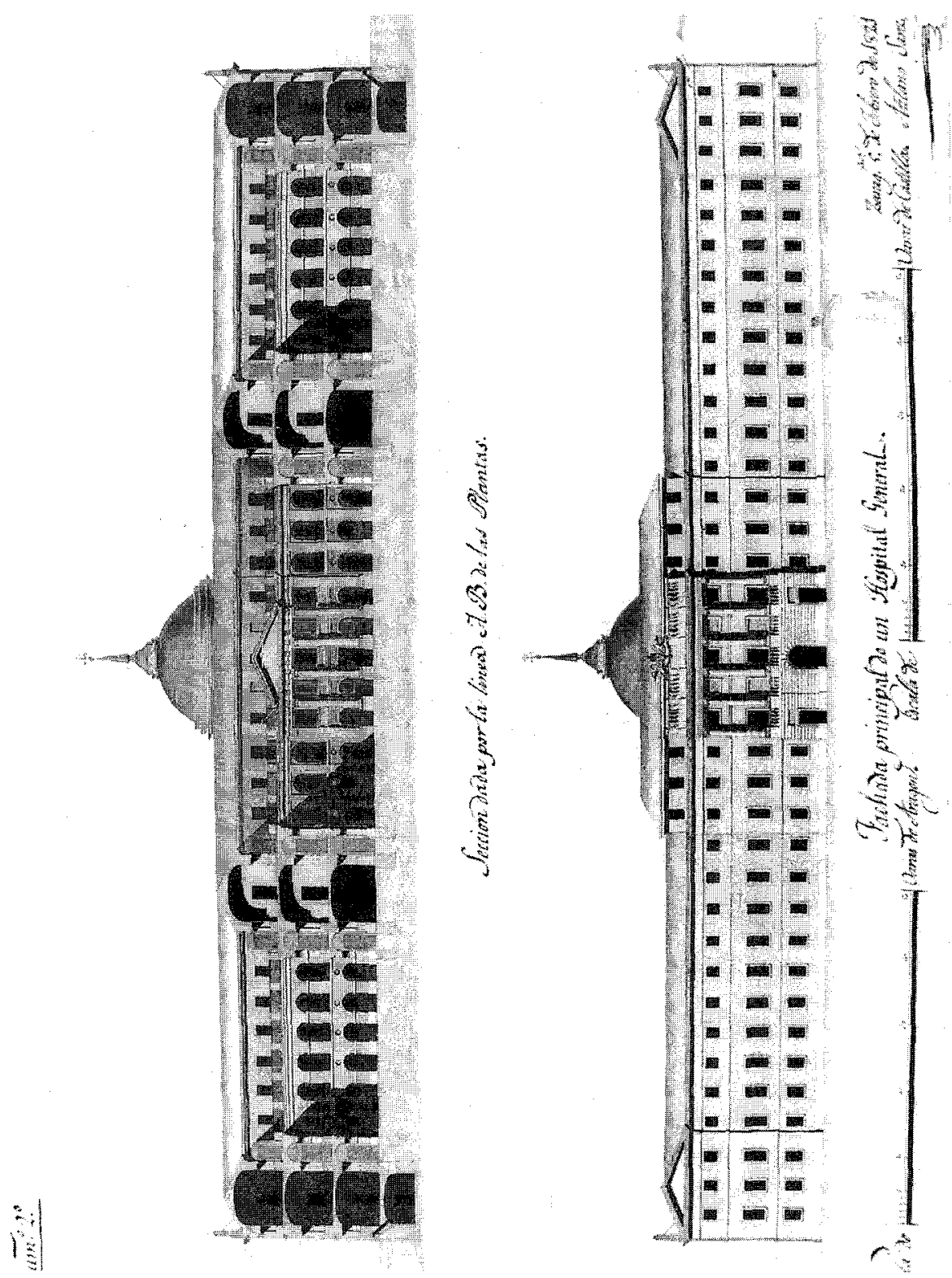

Fig. 2. Prueba de Pensado de D. Atilano Sanz.

Zaragoza, 5 de febrero de 1821. Fachada principal de un Hospital General. Real Academia de Bellas Artes de San Fernando. Sala de Planos, A-2452. 


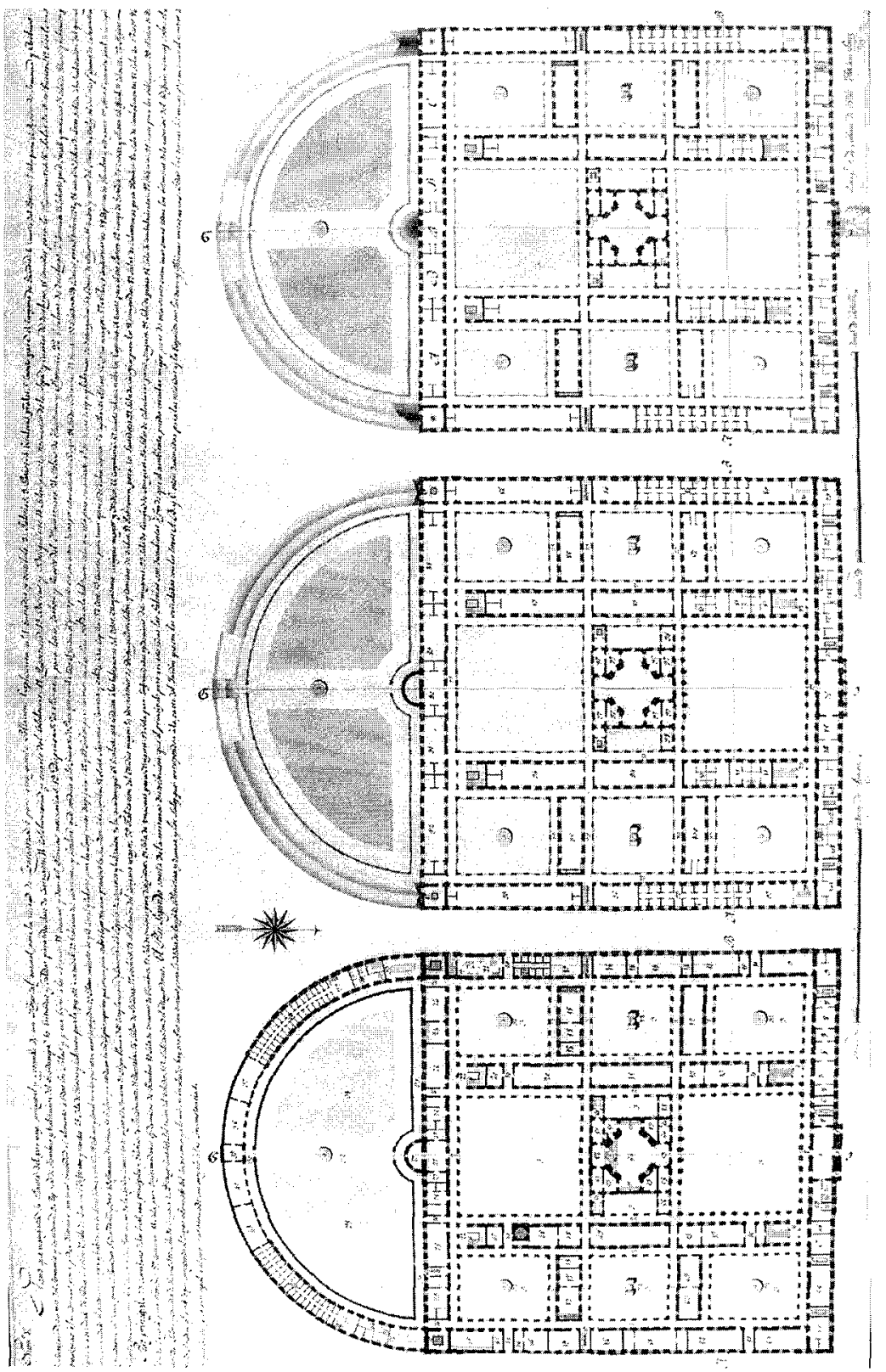

Fig. 3. Prueba de Pensado de D. Atilano Sanz. Zaragoza, 5 de febrero de 1821. Plano de la planta del piso bajo, principal y segundo de un Hospital General. Real Academia de Bellas Artes de San Fernando. Sala de Planos, A-2451. 
hubiese posibilidad de que el aspirante supiese con anterioridad el tema que tenía que desarrollar y preparárselo de antemano.

Además de las PRUEBAS DE PENSADO y de las de REPENTE, los aspirantes a poder medir, tasar, dirigir fábricas etc., debían presentarse en la Academia el día señalado por la misma para ser examinado. Esta tercera parte de los requisitos indispensables para graduarse, consistía en un examen oral ante un tribunal examinador, en el transcurso del cual se cotejarían los planos hechos de repente con los realizados de pensamiento, preguntándosele al candidato sobre cada uno de ellos y acerca de la teoría y práctica de la Arquitectura. Si el dictamen de los profesores por votación secreta era favorable al examinando, se le otorgaría el correspondiente título ${ }^{6}$.

Una vez aprobado y expedido el diploma, le eran concedidas al arquitecto amplias facultades para poder medir, tasar, idear y dirigir toda clase de obras públicas y particulares, tanto en lo civil como en lo hidráulico sin excepción ni limitación alguna en todos los dominios de S.M.. Además «serán los Arquitectos, Maestros mayores de las Ciudades, Capitales y subalternas, Santas Iglesias e Intendencias del Reino; y sólo en oposición con Académicos de mérito en las Ciudades, Capitales e Intendencias y Santas Iglesias de primer orden, tendrán éstos la preferencia que se menciona en el artículo octavo del Capítulo primero con conocimiento de la Real Academia ${ }^{7}$. No solamente se les concedian amplias competencias sino que también se les eximía de "Levas, Quintas, Reclutas, alojamiento de tropas, repartimientos, tutelas, curadurías, rondas, guardias y todas las demás cargas concejiles como por Estatuto está concedido a los discípulos, pensionados o que hayan ganado premio, sin que puedan ser obligados por ningún juez o tribunal a incorporarse en Gremio alguno, ni a ser vi-

6 Es totalmente obligatorio para conocer adecuadamente la organización de la Academia de Bellas Artes de San Fernando, su compleja Comisión de Arquitectura y los exámenes para las distintas profesiones de la arquitectura referirse al Dr. D. José Enrique GARCíA MELERO y sus artículos siguientes reseñados por orden cronológico de publicación: «Cartas a Bosarte desde Roma (Correspondencia de Pedro García de LA Huerta, Azara, Silvetre Pérez y Mengs con el secretario de la Academia de San Fernando)". En: Academia, Boletín de la Real Academia de Bellas Artes de San Fernando, núm. 79, primer semestre de 1990, pp 337-382. "Arquitectura y burocracia (1786-1808)". En: Espacio, tiempo y forma, 1. 4. Madrid, Departamento de H.a del Arte UNED, 1991, pp. 183-384. "Los orígenes académicos del romanticismo español: malestar y crisis en torno a 1792". En: Espacio, tiempo y forma, serie VII, t. 5. Madrid, Departamento de H. a del Arte de la UNED, 1992, pp. 211-262. «El debate académico sobre los exámenes para las distintas profesiones de la Arquitectura (1781-1783). (El arquitecto según Juan de Villanueva)". En: Espacio, tiempo y forma, serie VII, t. 6. Madrid, Departamento de $\mathrm{H}^{\text {a }}{ }^{\mathrm{del}}$ Arte de la UNED, 1993, pp. 325-377.

7 A.A.S.F. Ordenanza Artística. Capítulo Segundo. Artículo 13, op. cit. 
sitados por veedores o sindicos exerciendo libremente su profesión sin más licencia ni título que el librado a su favor por la Real Academia»".

Una vez examinados los aspirantes a la graduación de arquitecto de los tres ejercicios, prueba de pensado, prueba de repente y ejercicio oral sobre cada uno de los anteriores y sobre la teoría y la práctica de la Arquitectura, si eran aprobados se les concedía el correspondiente certificado firmado por el Secretario de la Academia, y a partir de 1818 el correspondiente título de arquitecto, que podríamos decir que ya se asemeja a lo que es un título de corte moderno. Ambos por supuesto, con la misma valoración académica.

Desde que se publicó la Real Orden de 28 de agosto de 1816, hasta el siguiente reglamento de S.M. la reina Isabel II aprobado el 17 de mayo de 1848 , se titularon 357 arquitectos $^{9}$. Este nuevo reglamento aprobado por S.M. la reina y su ministro de instrucción pública Bravo Murillo para los ejercicios que deben practicar los alumnos de la Escuela Especial de Arquitectura para obtener el título de arquitecto, tendrá como diferencia con la época anterior, que ya se había fundado en 1844 la que retomaría los estudios y preparación de la carrera de arquitectura, la reciente fundada Escuela Especial de Arquitectura. Este nuevo reglamento se componía de XVI artículos, dejando claro en los mismos, tanto el número de años de que se componía la carrera de arquitectura, como el coste y carta de pago para obtener el título o los ejercicios que tenían que realizar aquellos alumnos que no hubiesen realizado todos sus cursos en la reciente creada Escuela Especial de Arquitectura ${ }^{10}$, como pone de manifiesto los siguientes artículos:

ARTICULO I. Sólo obtendrán el título de arquitecto los discípulos que habiendo sido aprobados del quinto curso de la carrera, acreditasen por certificación de uno o más arquitectos aprobados, haber adquirido la práctica de la profesión (artículo 77 del reglamento de la Escuela).

ARTICULO III. Los alumnos que aspiren al título de Arquitecto presentarán solicitud pasado el mes de agosto del segundo año de práctica... Y carta de pago de 2.000 reales de derecho de título.

8 lbídem, Artículo 14.

9 A.A.S.F. Libro de arquitectos 3/154. También se puede comprobar los listados en el «índice de los Arquitectos aprobados por la Real Academia de San Fernando por orden alfabético" en el legajo 68-5/4, pp. 2-10 anverso y reverso.

10 Real Academia de Bellas Artes de San Fernando. Ejercicios para obtener el título de arquitecto. Reglamento (17 de mayo de 1848). Signatura F-4777. 


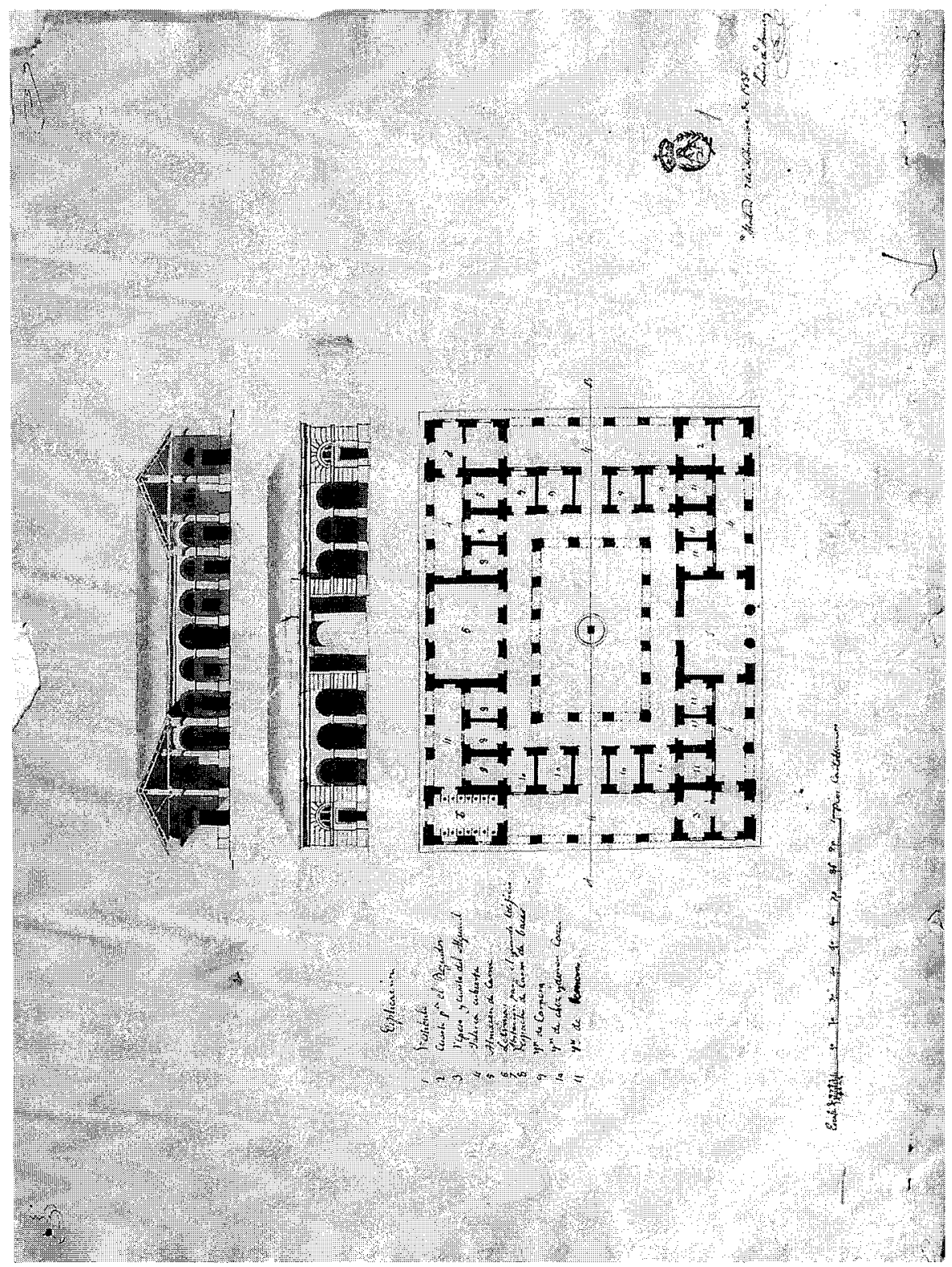

Fig. 4. Prueba de Repente de D. Luis Araúco. Madrid, 7 de noviembre de 1873. Tema $n .{ }^{\circ}$ 109. "Una carnecería para una ciudad principal". (Libros de Asuntos para Arquitectos. Signatura A.A.S.F. 3/333). Real Academia de Bellas Artes de San Fernando. Sala de Planos, A-2261. 
ARTICULO IV. EI Secretario General a los tres días de presentada la solicitud acompañada del respectivo expediente.... fijará en el término de tres días aquel en que el aspirante debe principiar sus ejercicios y convocando al efecto la junta de profesores.

ARTICULO XV. Quedan relevados de estos ejercicios los alumnos de la Escuela Especial de Arquitectura que hayan concluido en ella todos sus estudios, obtenido por oposición pensiones por el Gobierno para estudiar en el extranjero y remitido sin interrupción los trabajos de reglamento, pero no podrán solicitar el título hasta que hayan trancurrido dos años que se considera en este caso conmutados con los de la práctica.

Todos estos artículos del nuevo Reglamento, ponen de manifiesto el cambio que van a experimentar los estudios de arquitectura y la nueva normativa para obtener el título a partir de la creación de la Escuela Especial de Arquitectura.

La Real Academia de Bellas Artes de San Fernando, a través de su Sección de Arquitectura creada el 23 de abril de 1846 y que sustituye a la denominada Comisión de Arquitectura fundada el 22 de marzo de 1786 por una Real Cédula con la firma del conde de Floridablanca, será la encargada de examinar a aquellos discípulos, que por haber cambiado los planes y años de estudios de esta disciplina, van a tener que pasar por un examen de reválida. Dichos exámenes se realizarán hasta el año 1858, produciéndose la dicotomía entre los alumnos que cursaban los cinco años de carrera y los dos de prácticas en la Escuela Especial de Arquitectura y los discípulos que por pertenecer al plan de estudios anterior, los examinaba la Sección de Arquitectura de la Real Academia de San Fernando, compuesta por una Junta de tres profesores, que los examinaba de los conocimientos artísticos y científicos, además de presentar un proyecto arquitectónico y su correspondiente memoria descriptiva.

A continuación se detallan 446 arquitectos aprobados por la Real Academia de Bellas Artes de San Fernando desde 1814 hasta 1858, último año en que examina la Academia para otorgar el título de esta disciplina académica. Se acompaña, también, un resumen general con los edificios más elegidos por los arquitectos, así como un gráfico con el análisis comparativo de las diferentes Pruebas de Pensado.

Desde 1814 hasta 1850 los exámenes realizados por los aspirantes al título, eran homogéneos. No así a partir de este año y hasta 1858, en los que por estar ya en funcionamiento la Escuela Especial de Arquitectura y el nuevo Reglamento aprobado el 17 de mayo de 1848 se siguen criterios no tan homogéneos e incluso distintos. 
En las listas de los arquitectos aprobados se reseña primeramente el legajo, y a continuación el nombre del arquitecto, el lugar de nacimiento, la edad, la junta ordinaria en la cual fueron aprobados, la junta de examen y temas que les salieron como prueba de repente y la elección que ellos hicieron de uno de los tres temas salidos al azar, así como la prueba de pensado, llamada también informe práctico facultativo. Lleva también el apartado de PROV.(Provincia) cuya numeración corresponde a los actuales códigos provinciales. Esta numeración permite en una rápida ojeada comprobar, por ejemplo, la cantidad de arquitectos naturales de Madrid (código 28) o de Vizcaya (48), Guipúzcoa (20) o de Barcelona (08).

Las fundaciones de las academias, y concretamente la de San Fernando, constituirán una de las contribuciones más innovadoras del siglo XVIII español. La docencia llevada a cabo en los talleres artesanales, será sustituída por la de las academias, elaborándose planes académicos en los que la preparación técnica se completará con las diversas disciplinas que ampliarán la formación cultural de los alumnos. Además ofrecerán a los jóvenes la posibilidad de recibir una educación gratuita. Y se exigirán los títulos otorgados por ellas - como opina D. Francisco José León Tello- para poder ejercer el ejercicio profesional ${ }^{11}$. Pero sobre todo se les va a encomendar la censura estética.

$Y$ es precisamente en el deseo de acabar con los «desmanes» del barroco y de implantar el clasicismo en España, donde quizás esté el germen de las Reales Academias, y concretamente la de San Fernando, fundada por el tercer Borbón Fernando VI el 12 de abril de 1752. Podemos decir que nacieron como causa principal para luchar contra lo que aquella sociedad diciochesca creía que era la decadencia de las Bellas Artes.

El listado, que se publica a continuación, se ha obtenido de la consulta de numerosos legajos del archivo de la Real Academia de Bellas Artes de San Fernando. Su difusión parece oportuna para conocer tanto los distintos arquitectos que aprobaron sus exámenes en este instituto madrileño durante el período comprendido entre los años 1814 y 1858 como, sobre todo, los temas arquitectónicos que preocupaban en la Academia al doble rival conceptual y pragmático. Se piensa que tales asuntos pueden contribuir -junto con las publicaciones teóricas salidas a la luz entonces- a proporcionar una idea mucho más exacta del pensamiento del llamado período del romanticismo histórico español. En estas pruebas se hallan

11 León Tello, F.J. y Virginia SANz, M.M.: La estética académica española en el siglo XVIII. Real Academia de Bellas Artes de San Carlos de Valencia: Valencia, 1979. 
las bases ideológicas de consulta obligada para el estudio de las distintas tipologías y de aspectos tan interesantes como, por ejemplo: del uso de los diferentes materiales, del empleo de los órdenes, de la incidencia de los tratados, de las relaciones estrechas existentes entre arquitectura y economía... También parece oportuno a fin de estudiar la profesión del arquitecto durante esos años, de la Academia y del academicismo y de su Comisión y Sección de Arquitectura, como organismo de gran incidencia en la teoría y en la práctica de la arquitectura del romanticismo. El inventario se ha realizado con una pretendida finalidad pragmática: facilitar al estudioso la localización de los expedientes de los arquitectos y de los discursos en este archivo de la Academia. 


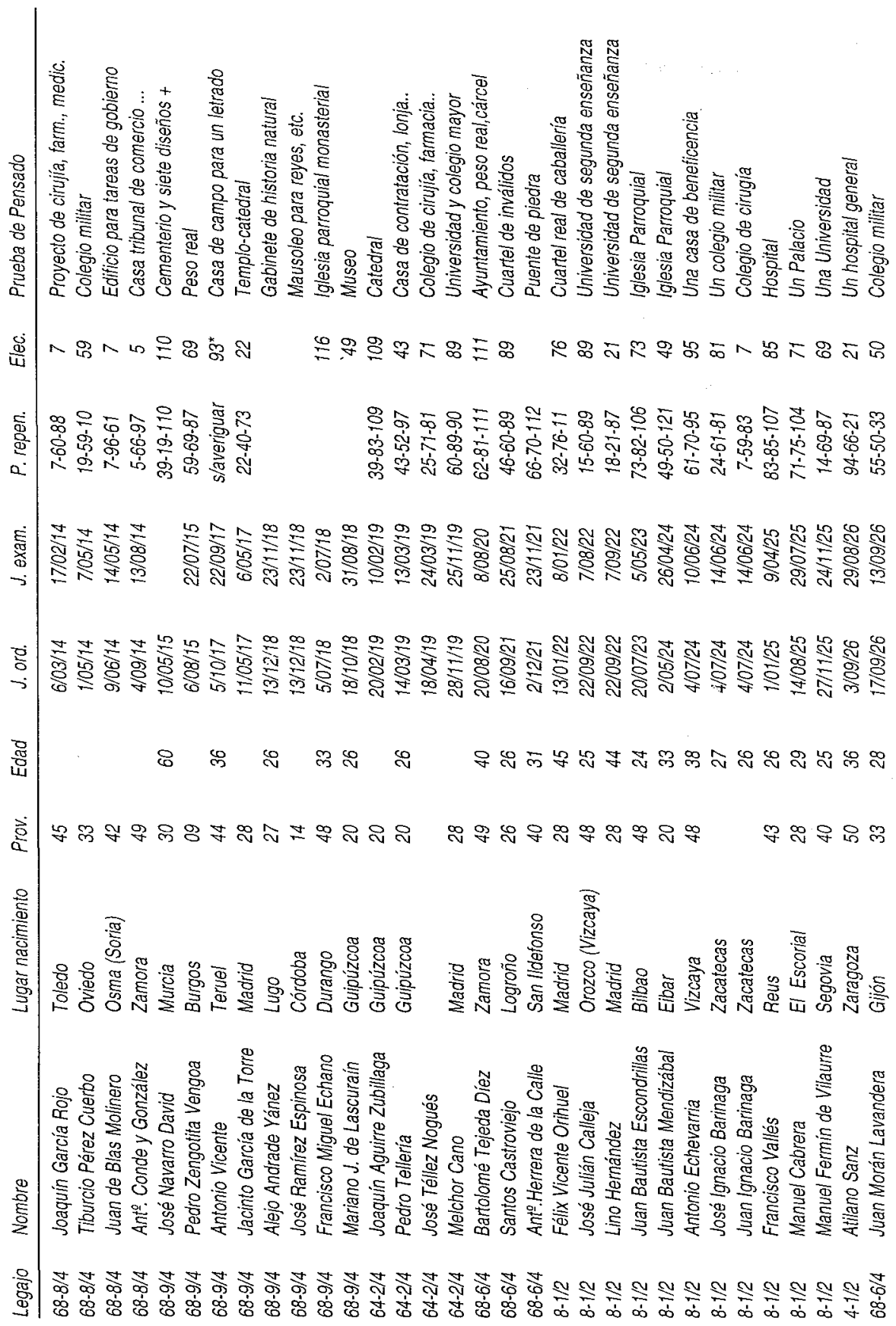




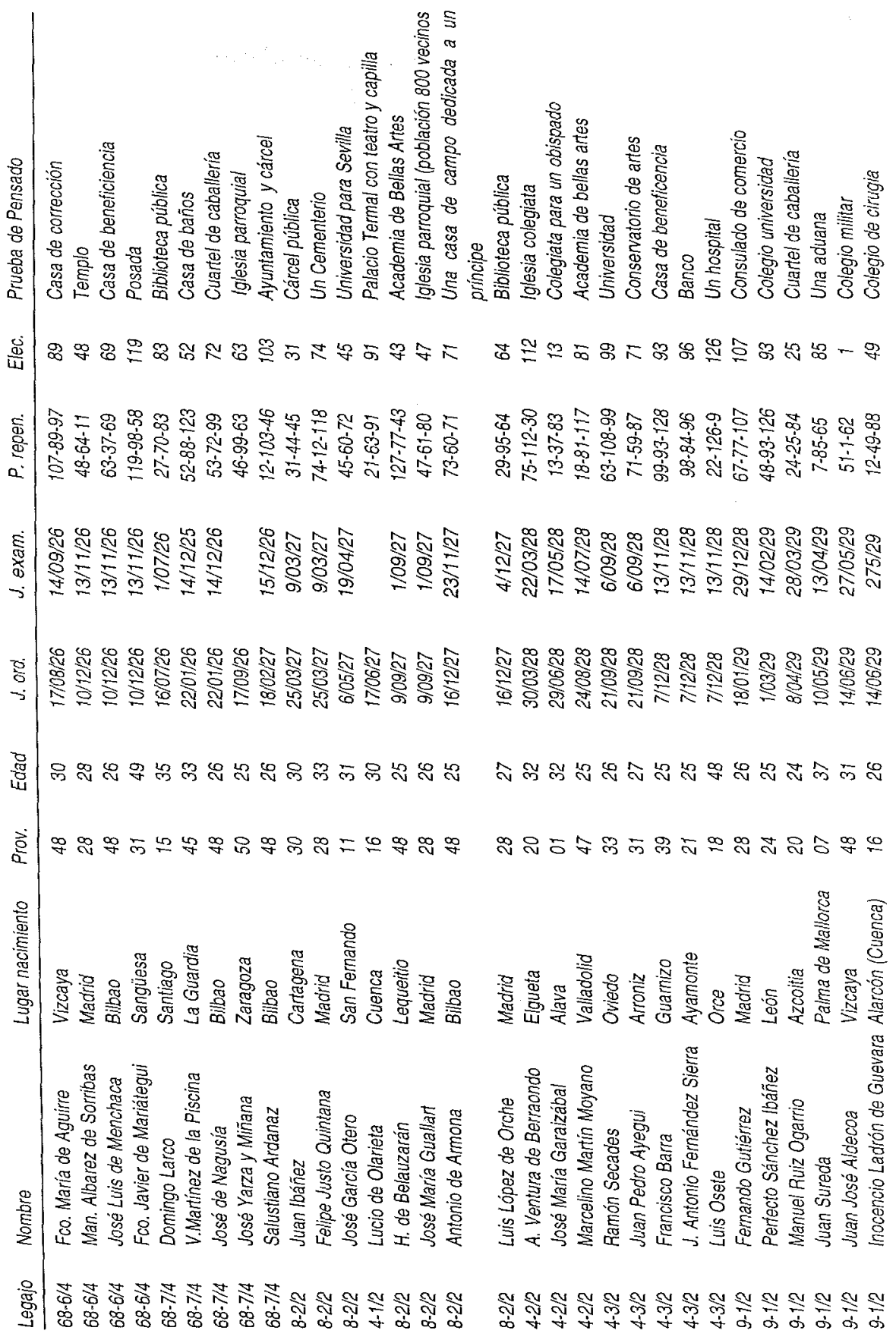




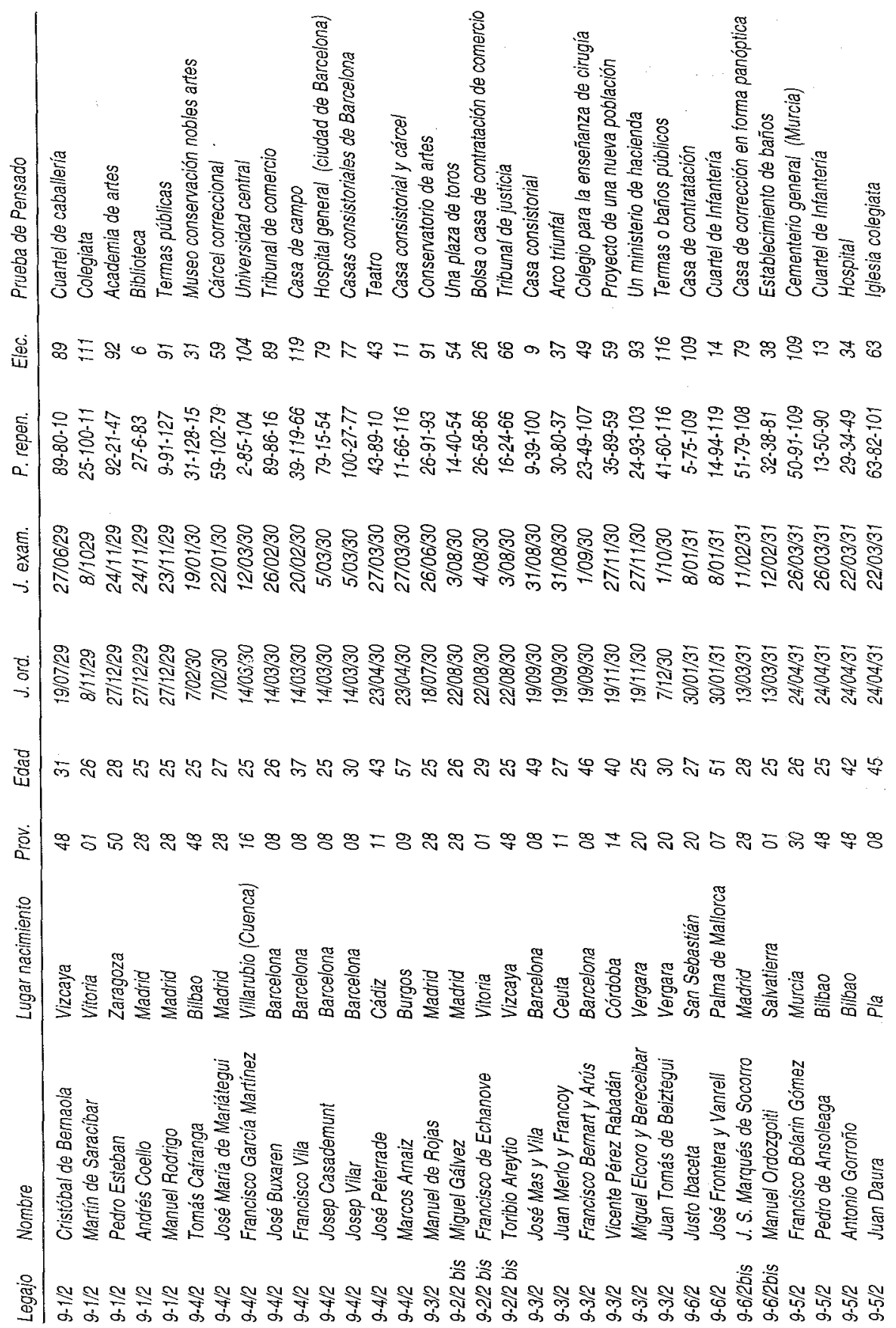




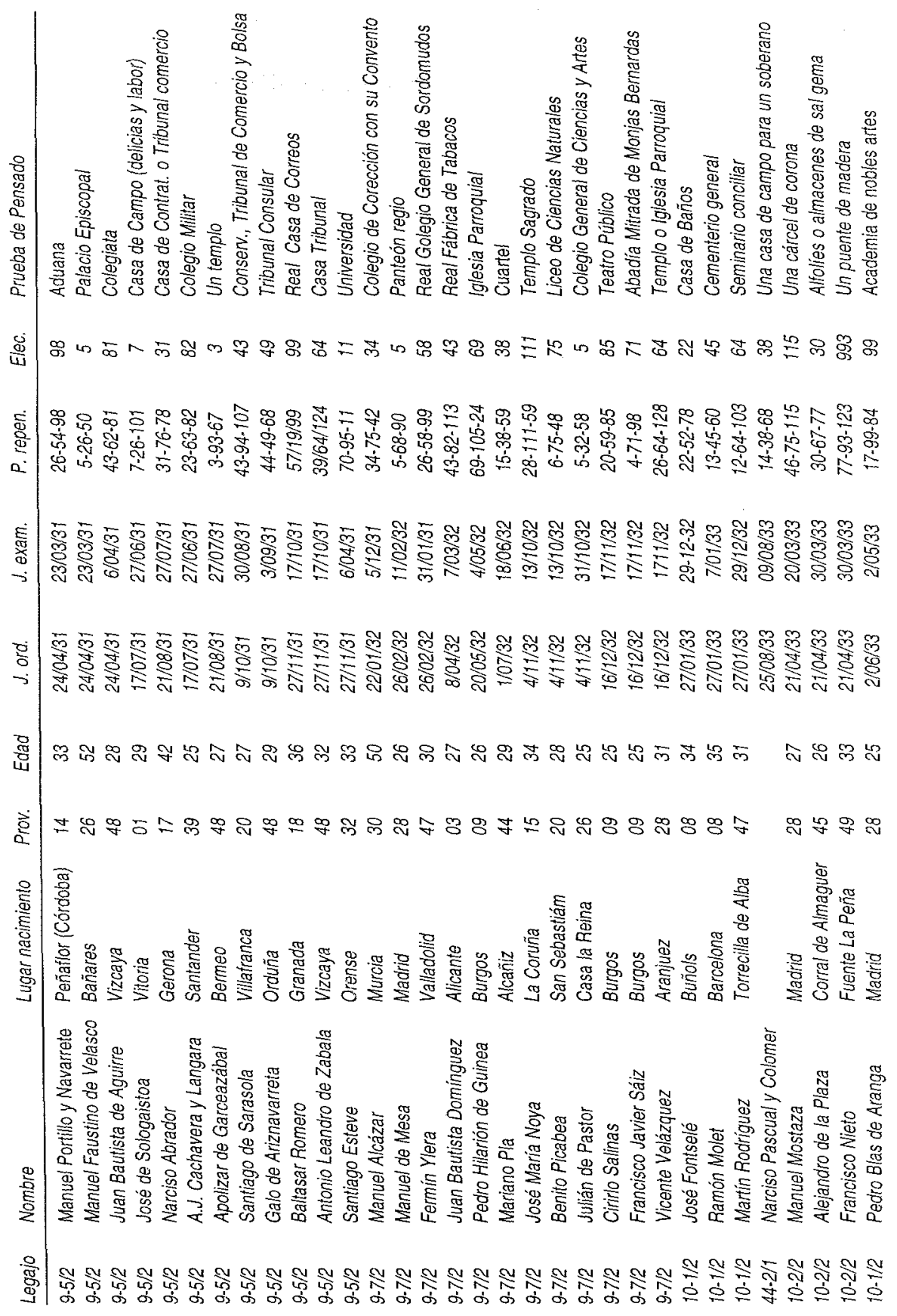




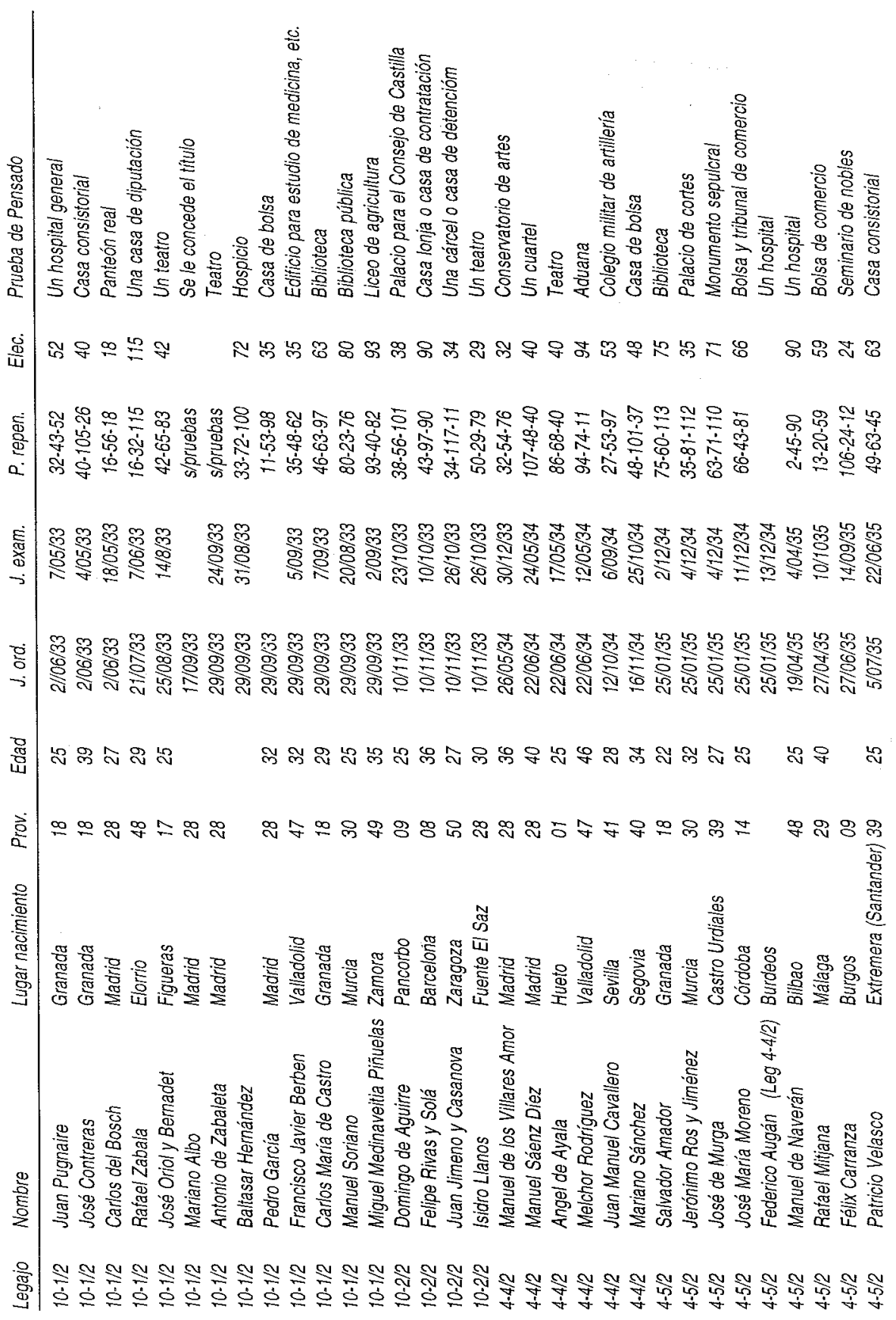




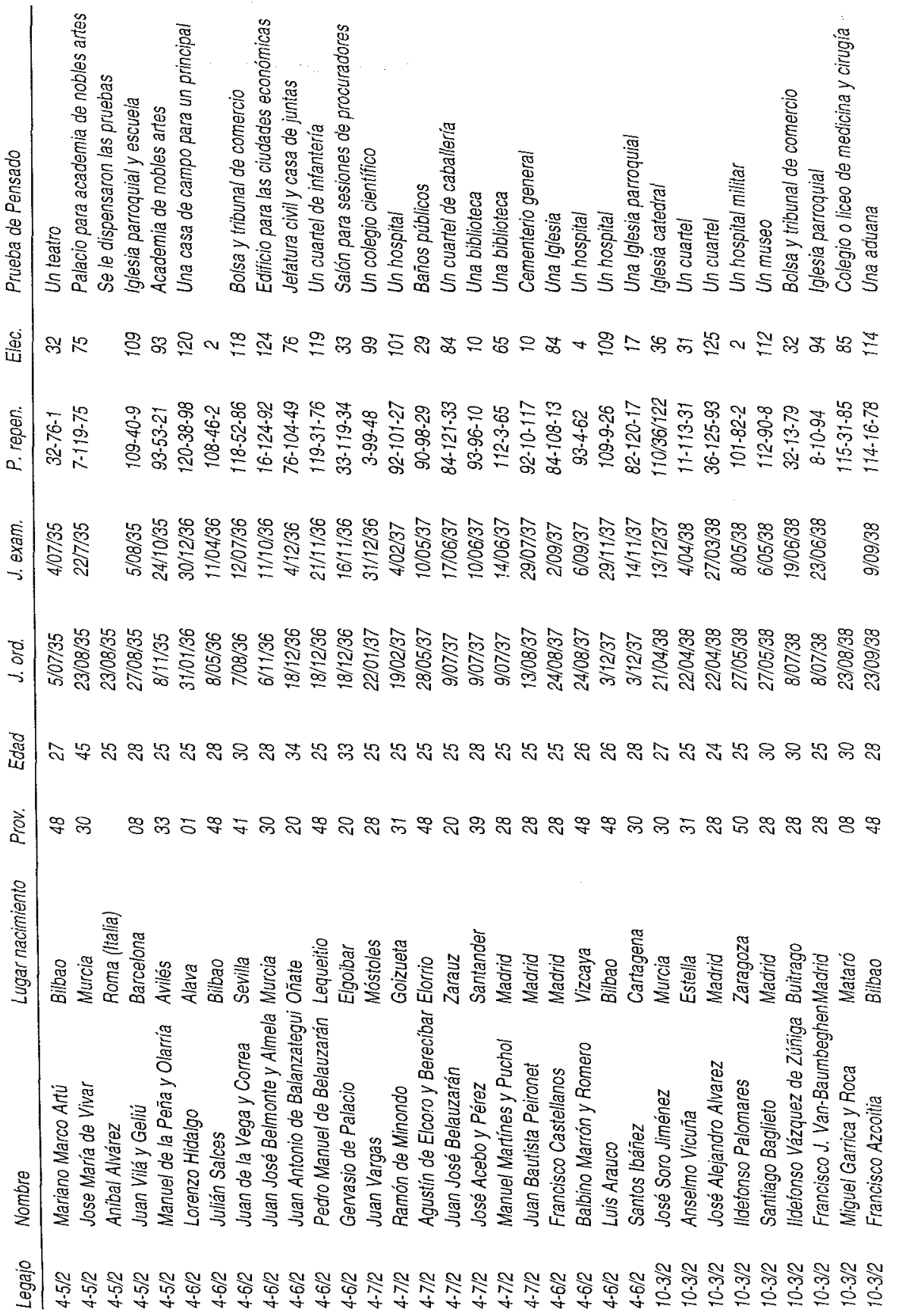




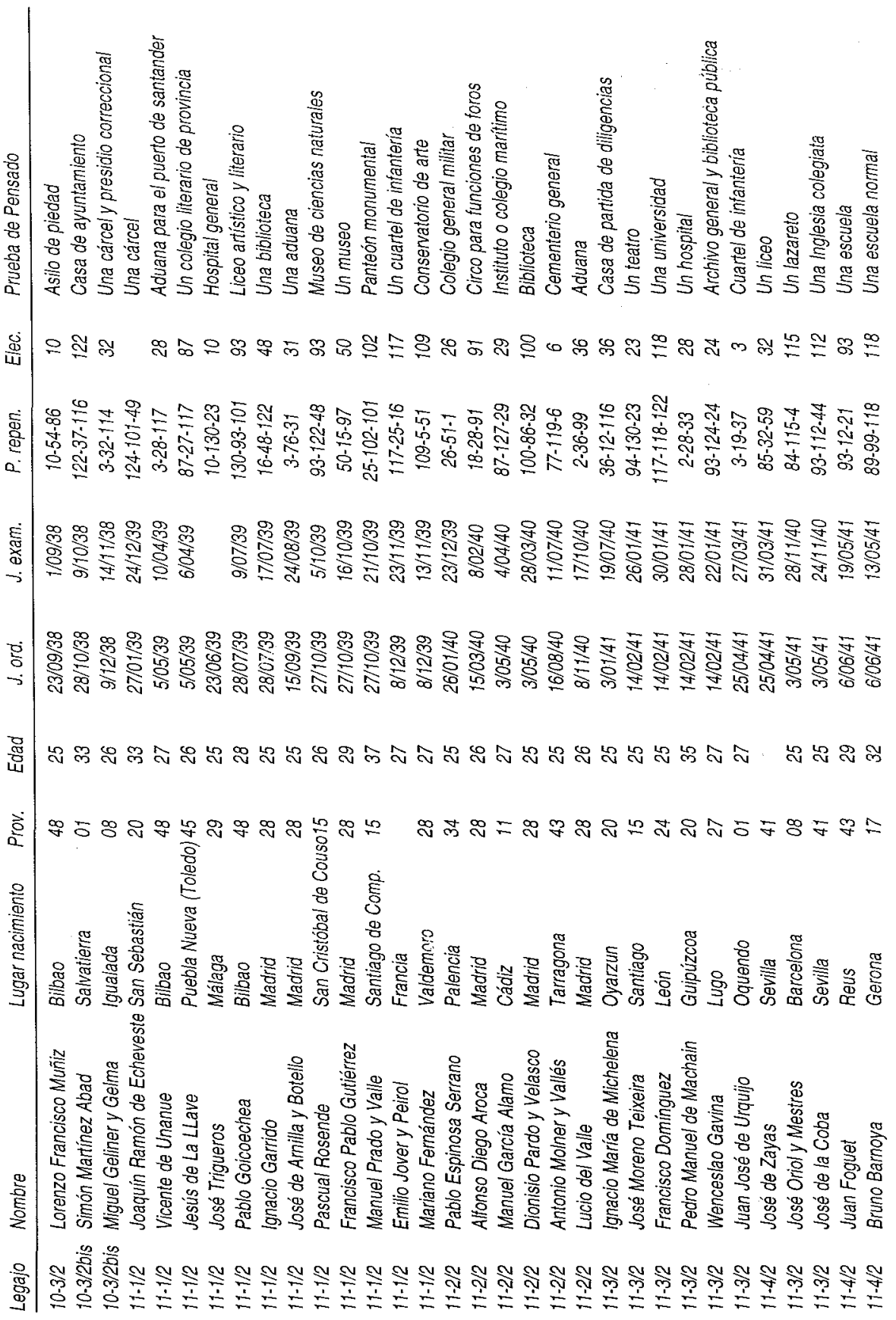




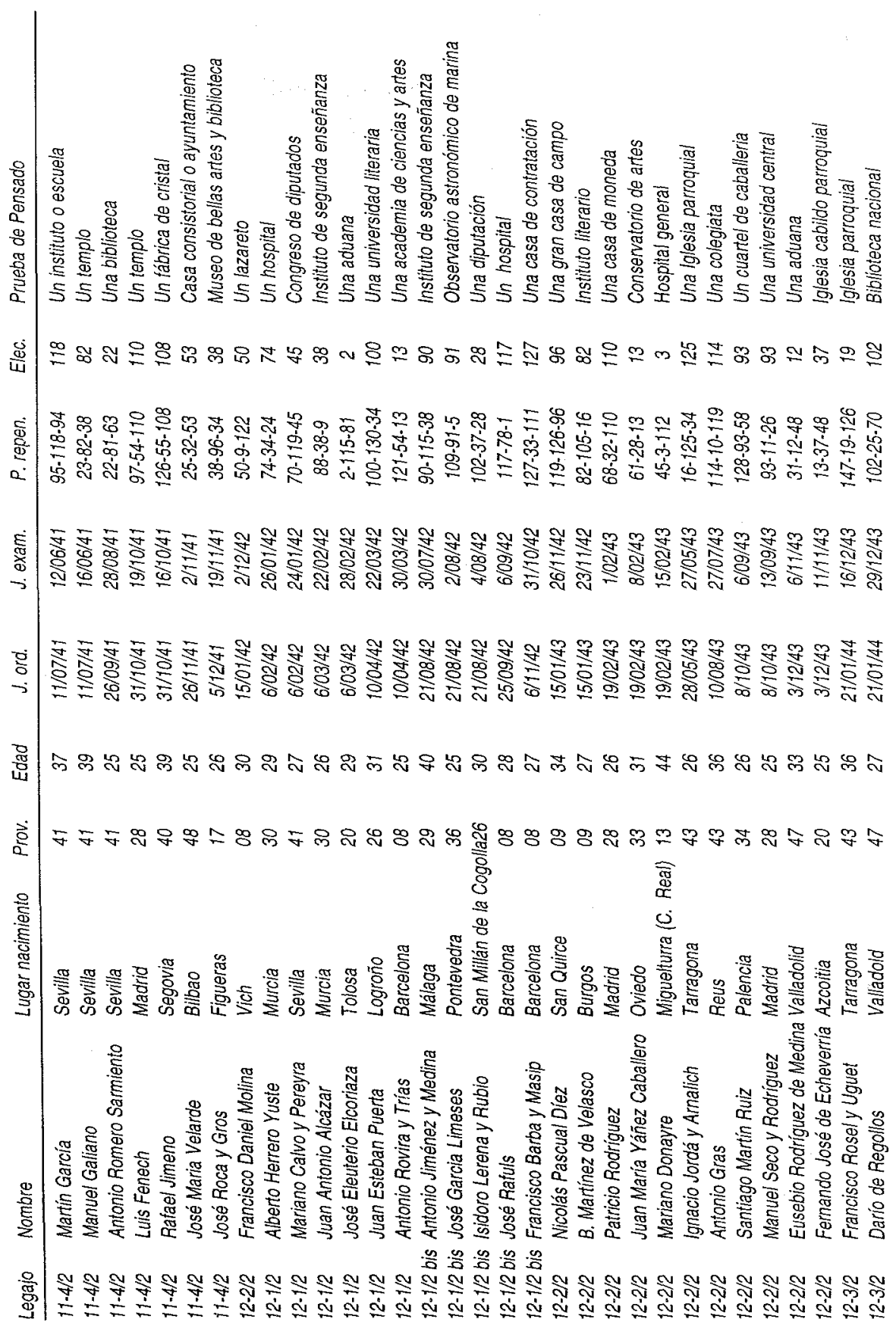




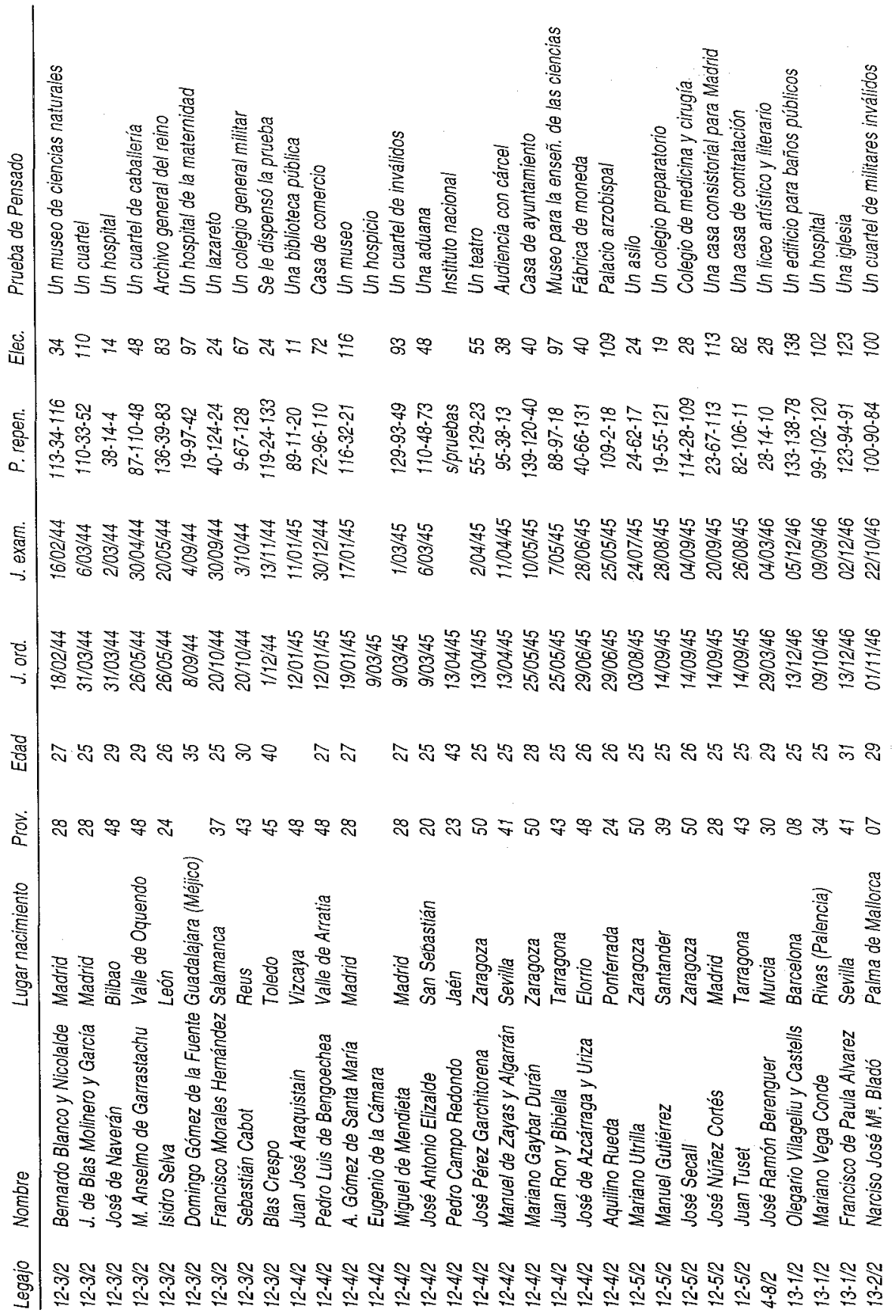




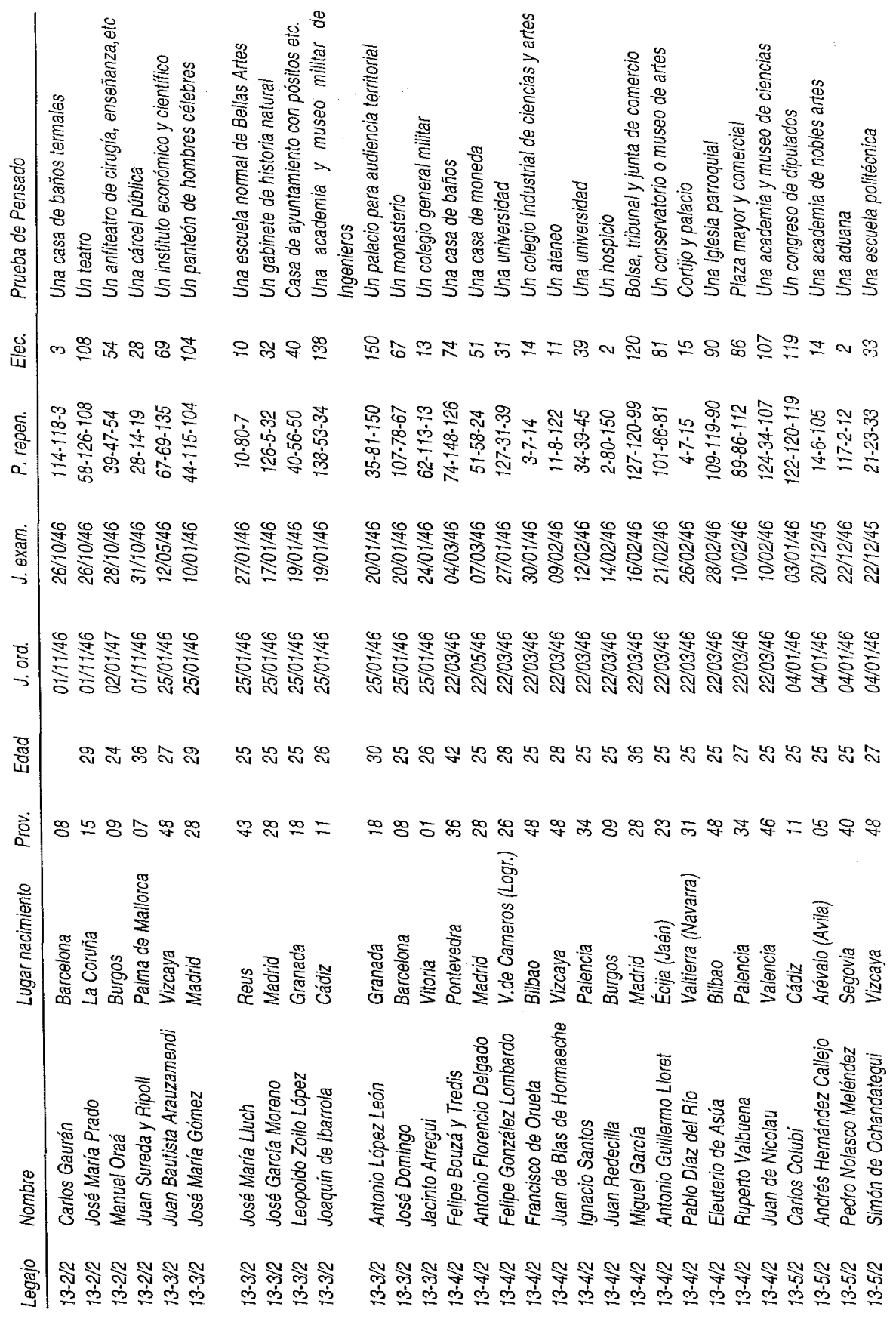




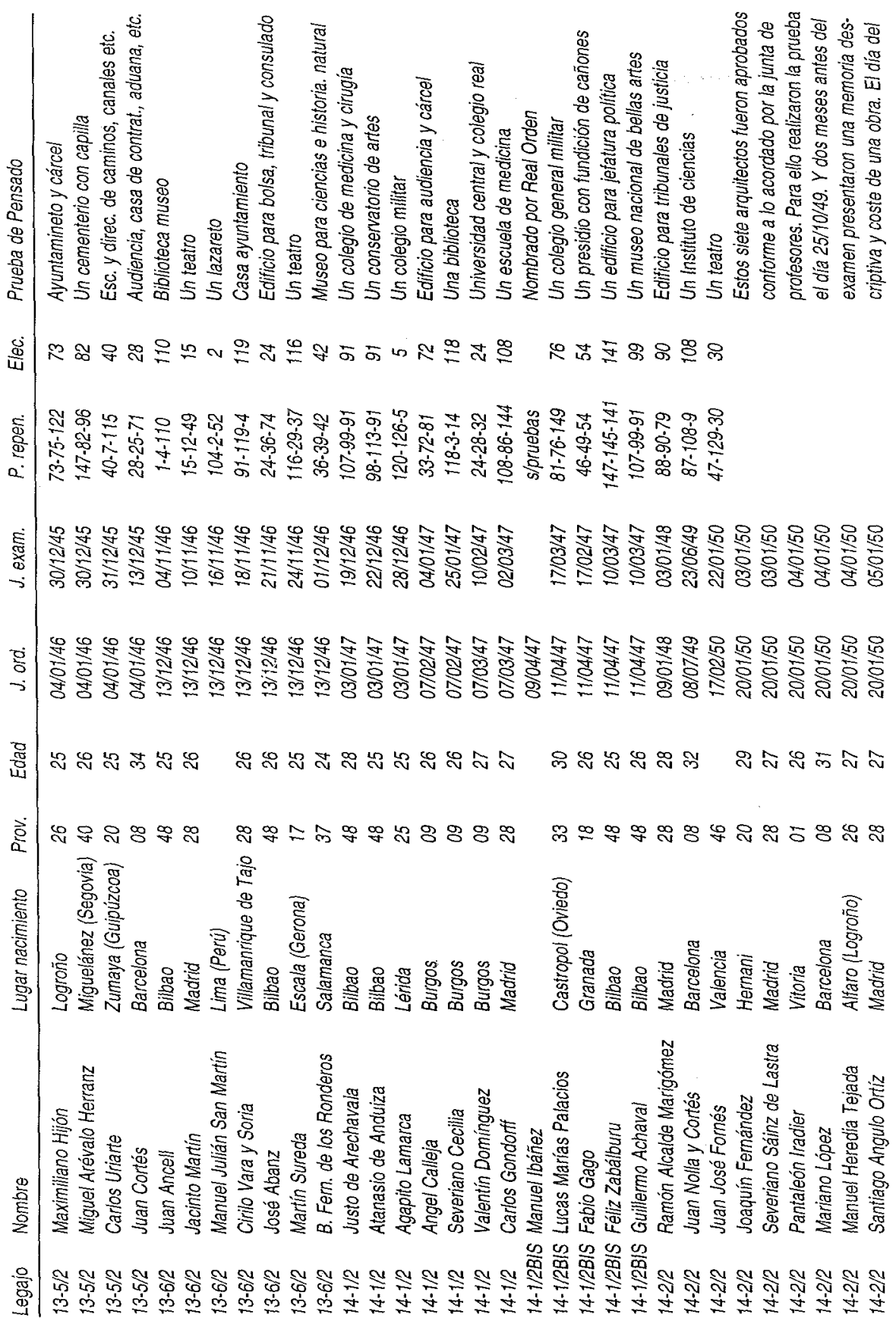




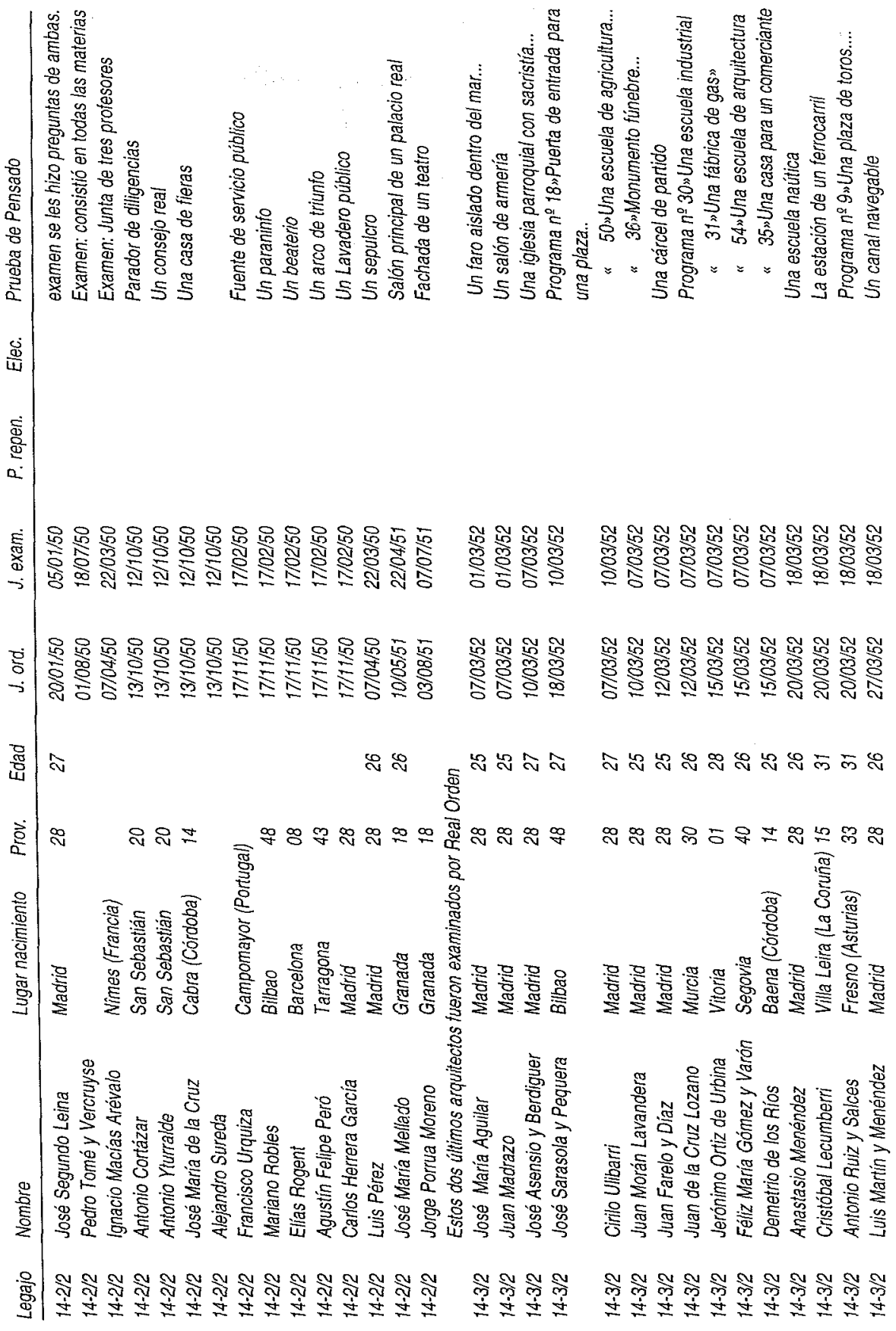




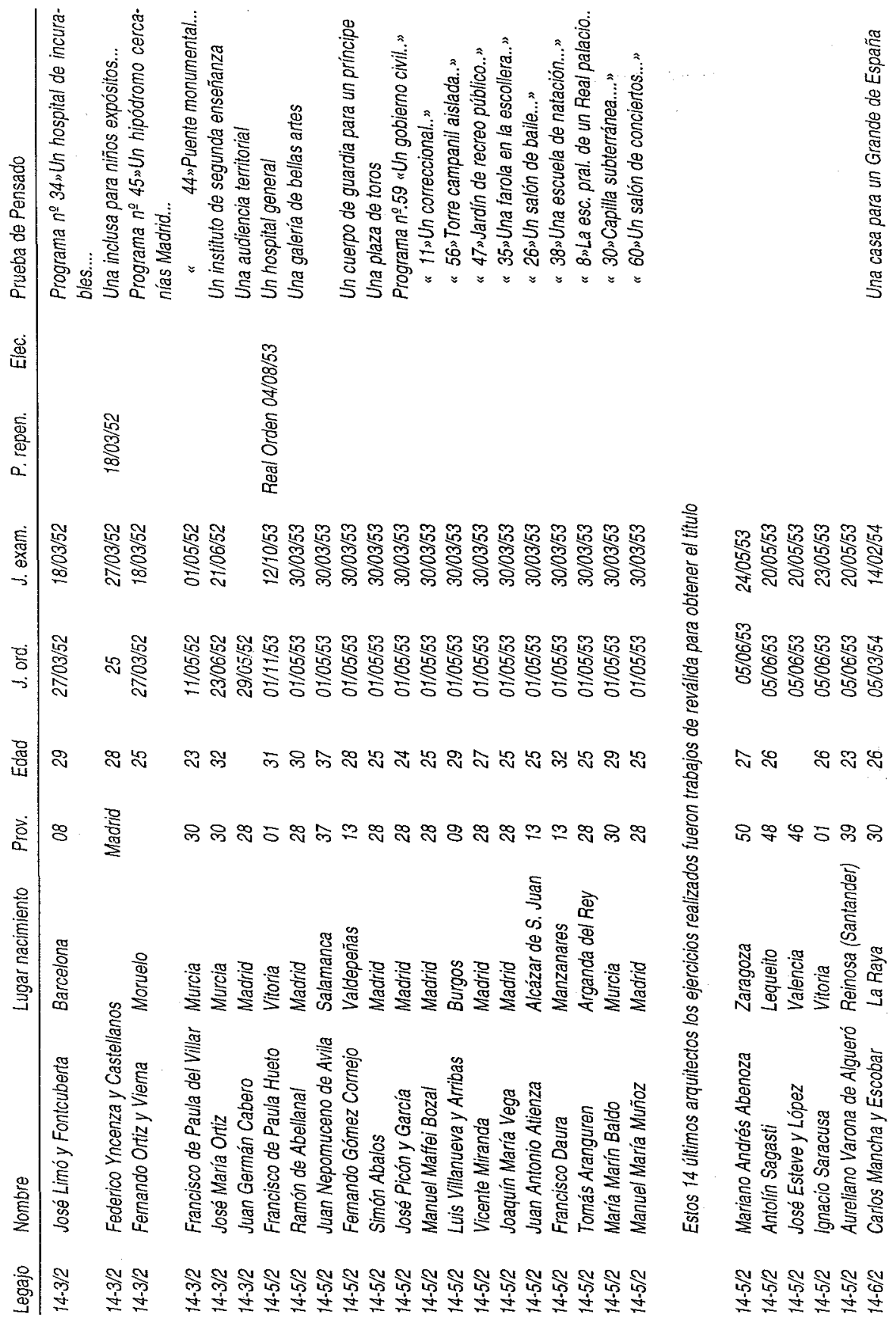




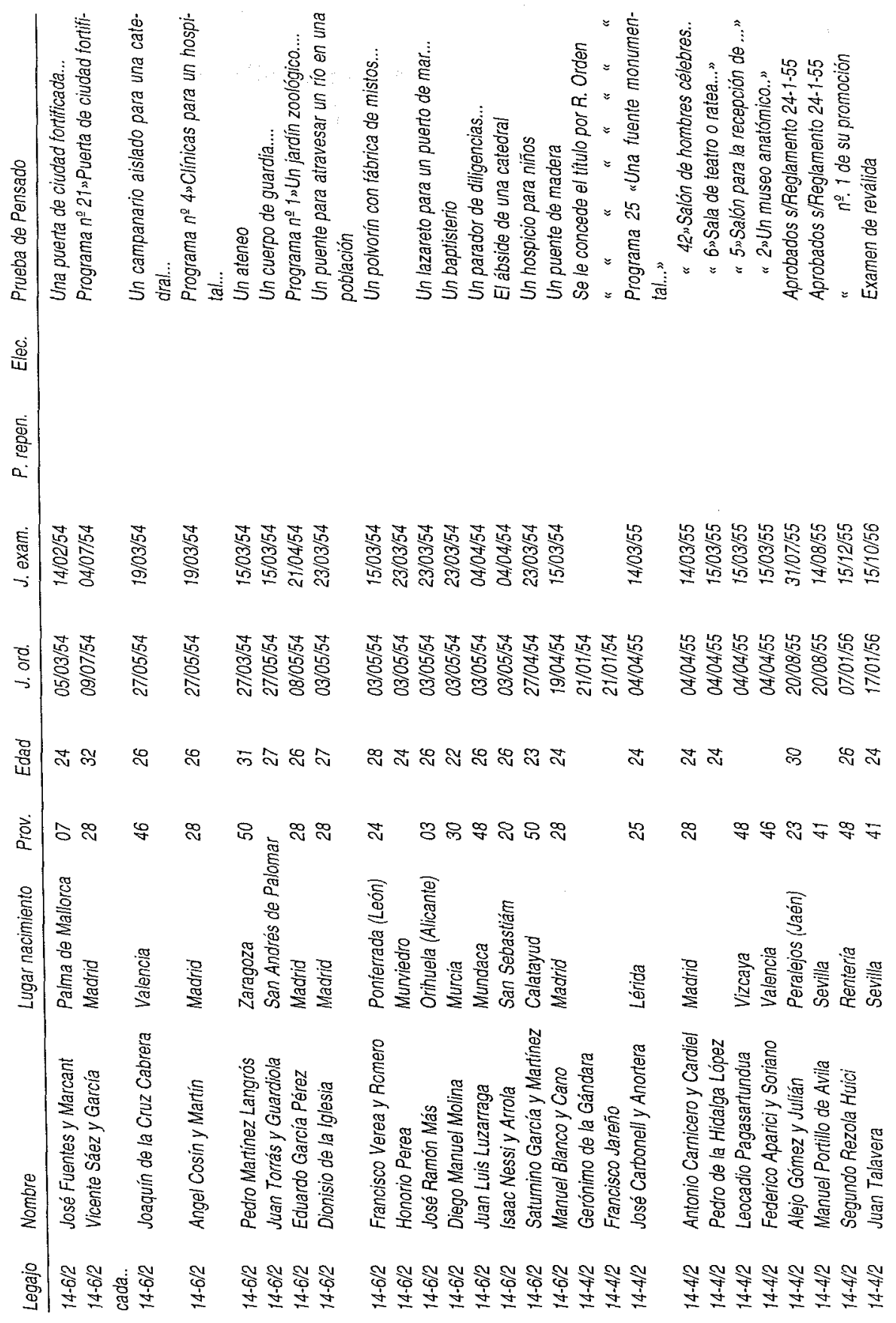




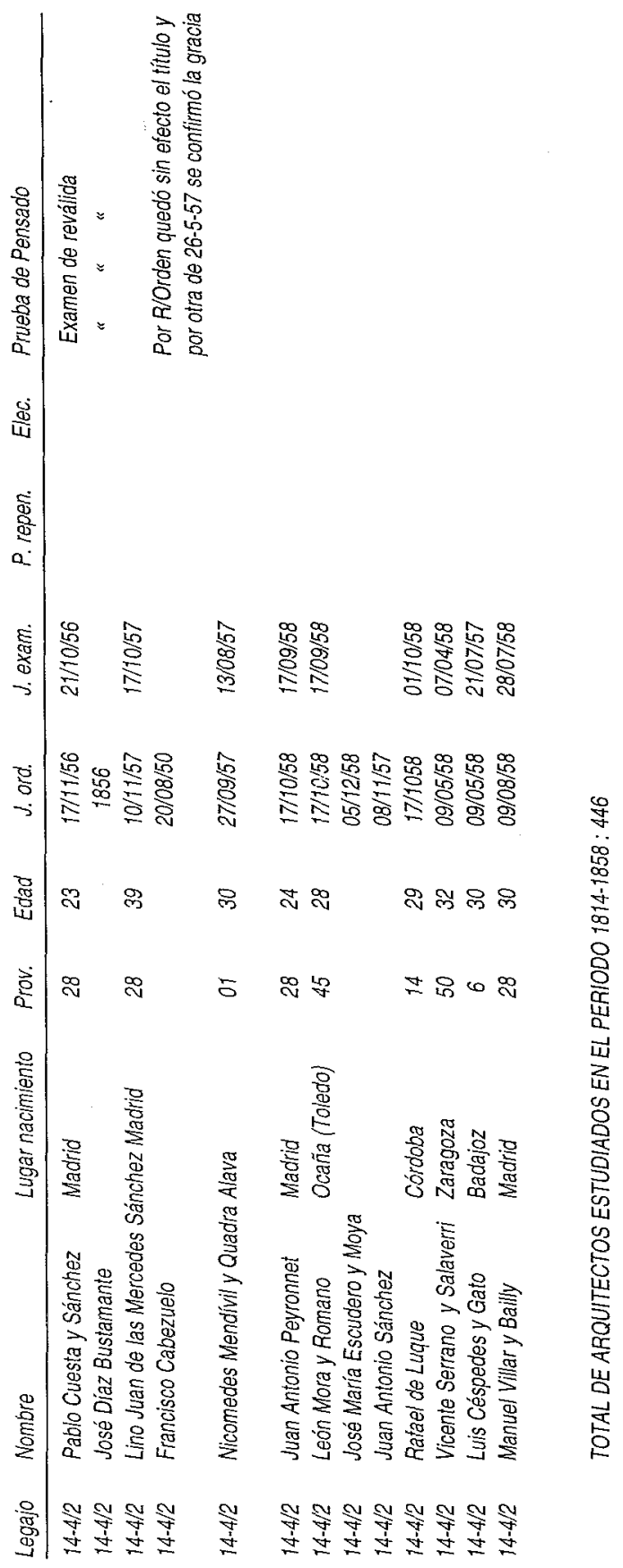




\section{RESUMEN GENERAL}

Total arquitectos estudiados

Examinados con PRUEBAS DE PENSADO

Arquitectos aprobados pero sin haber encontrado

la Prueba de Pensado o por estar eximidos de ella

\section{PRUEBAS DE PENSADO}

Centros de enseñanza (liceos, colegios, academias, universidades, institutos, etc.)

$77 \quad 19 \%$

Edificios religiosos (iglesias, catedrales, colegiatas, abadías, templos, etc.)

$389 \%$

Edificios hospitalarios

$236 \%$

Museos $20 \quad 5 \%$

Cuarteles $19 \quad 5 \%$

Bibliotecas

$16 \quad 4 \%$

Cárceles $154 \%$

Teatros

$13 \quad 3 \%$

Cementerios

$7 \quad 2 \%$

Puentes

$5 \quad 1 \%$

Construcciones varias 


\section{ANÁLISIS COMPARATIVO DE DIFERENTES PRUEBAS DE PENSADO}

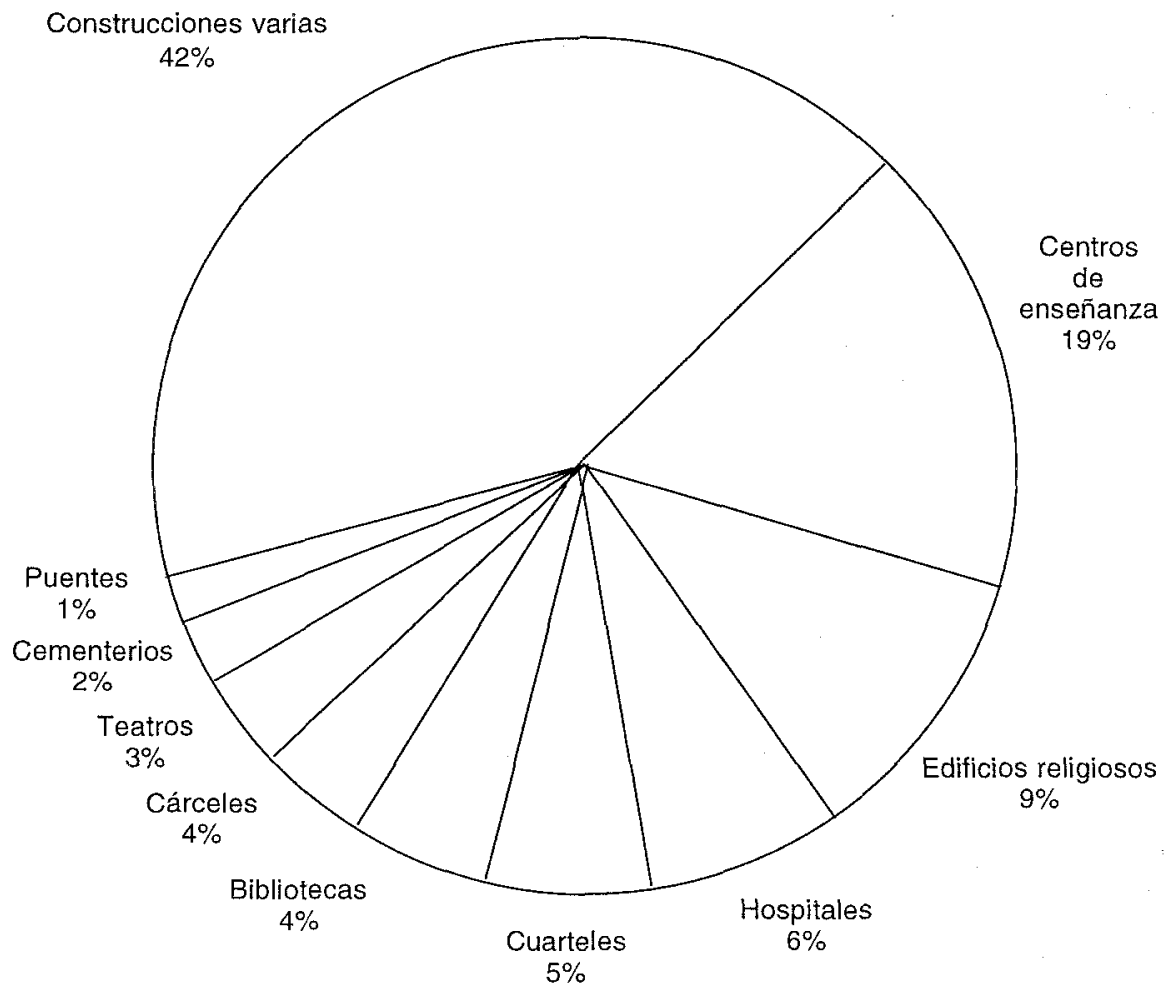


